\title{
The milliped family Striariidae Bollman, 1893. V. Stegostriaria dulcidormus, n. gen., n. sp., Kentrostriaria ohara, n. gen., n. sp., and the convergent evolution of exaggerated metazonital crests (Diplopoda, Chordeumatida, Striarioidea)
}

\author{
WILLIAM A. SHEAR ${ }^{1 *} \&$ PAUL E. MAREK ${ }^{2}$ \\ ${ }^{1}$ Professor Emeritus, Department of Biology, Hampden-Sydney College, Hampden-Sydney VA 23943 USA, current address: 1950 Price \\ Drive, Farmville VA 23901 USA. \\ !"wshear@hsc.edu; 은tps://orcid.org/0000-0002-5887-7003 \\ ${ }^{2}$ Department of Entomology, Virginia Tech, Blacksburg VA 24061 USA. \\ "= pmarek@vt.edu; ○ https://orcid.org/0000-0002-7048-2514 \\ ${ }^{*}$ Corresponding author
}

\begin{abstract}
Two new genera and species, Stegostriaria dulcidormus (Trisariinae) and Kentrostriaria ohara (Striariinae), are described from Oregon and Idaho, respectively. The new species are distinct from any other striariids, and indeed from any other chordeumatidan millipedes, in having the second dorsal crests greatly enlarged, giving them a fanciful resemblance to stegosaurid dinosaurs. In spite of this similarity, the two species are so distinct they cannot be accommodated in the same genus or the same subfamily. The exaggerated metazonital crests are therefore attributed to convergent evolution. We present a key to the genera of the family Striariidae.
\end{abstract}

Key words: new genus, new species, Oregon, Idaho

\section{Introduction}

The millipede family Striariidae Bollman, 1893 is comprised of species unusual among chordeumatidan millipedes in having, among other unique characters, a series of 12 longitudinal crests on the metazonites of their trunk rings. A single genus, Striaria Bollman, 1888 occurs from the southern Appalachian Mountains west to Indiana, as well as in Idaho, but the Pacific Northwest of North America supports a rich fauna consisting of five distinct genera (Shear 2020), including the two described here. At least three other new genera remain to be described.

Despite having in common the pronounced elevation of the second set of crests on each metazonite, the single species included in each of the genera described below are distinct in so many characters that they cannot be accommodated in the same genus or subfamily. Stegostriaria dulcidormus n. gen., n. sp., for example, has an intercalary crest developed on more posterior rings between the midline sulcus and the usual first crest, giving a total of 14, rather than 12 crests on the more posterior metazonites, and has highly modified ninth legs in the males, more complicated than any yet seen in striariid species. Kentrostriaria ohara n. gen., n. sp. differs in lacking the intercalary crests, but also in the exaggeration of the third and sixth crests on some metazonites as well, while the ninth legs are of the typical striariid form. Further, the gonopods are so different in each of the species that it is difficult to homologize the parts of one with the other. The gonopod morphology places the two species in two different subfamilies, as explained below.

\section{Methods}

Specimens were field-preserved in 75\% ethanol. Morphological studies were done using an Olympus SZH stereomicroscope and an Olympus BX50 compound microscope equipped with Nomarski optics. Gonopods were tempo- 
rarily mounted on microscope slides in glycerine for study up to 400X magnification and drawings were made from these slides using a drawing tube on the BX50. For scanning electron microscopy (SEM), specimens were mounted on $12.7 \mathrm{~mm}$ diameter aluminum stubs, using double-sided carbon discs. These were sputter coated with a $40 \mathrm{~nm}$ thick layer of platinum and palladium, using a Leica EM ACE600 high vacuum sputter coater. SEM micrographs were taken with a FEI Quanta 600 FEG environmental scanning electron microscope. Photographs were edited and refined using GIMP, and plates were composed in InkScape.

Type specimens are deposited in the collection of the California Academy of Sciences, San Francisco, California, USA, along with the SEM stub, WS36-15, to be deposited later.

As recommended by Bond et al. (2021) we state explicitly that our species hypothesis is morphological. More broadly, we reason from the Biological Species Concept, which states that species are reproductively isolated populations. This concept predicts that species populations should not only be different, but also distinct; that is, there should be unbridged gaps in phenotypic characters between them. If these gaps are obvious (morphological) this is evidence of species status. We also hold that a comparative diagnosis of a taxon is a testable hypothesis, subject to evaluation by other lines of evidence.

A note on terminology: in previous papers in this series, we have referred to the short, ring-like podomere distal to the coxa on the first two pairs of legs as the trochanter, and the following (distally) long podomere as the prefemur. Some current usage in millipede works term this short segment as the prefemur and the following, longer one as the femur, thereby assuming no trochanter is present on these legs. In this paper, we adopt the latter terminology, but without taking a firm position on the serial homology of these podomeres, which remains, in our minds, an unresolved question.

\section{Abbreviations used in the figures}

$\begin{array}{ll}\text { aac } & \text { anterior angiocoxite } \\ \text { ab } & \text { anterior branch of angiocoxite } \\ \text { c (numeral) } & \text { numbered metazonite crests } \\ \text { cc } & \text { colpocoxite } \\ \text { cp } & \text { coxal process } \\ \text { cp2 } & \text { coxal process of legpair } 2 \\ \text { cf } & \text { coxal flask of legpair } 3 \\ \text { cx } & \text { coxa } \\ \text { cxl4 } & \text { coxal lobe of legpair } 4 \\ \text { cx (numeral) } & \text { coxa of numbered legpair } \\ \text { f1 } & \text { femur of legpair 1 } \\ \text { ic } & \text { intercalary crest } \\ \text { lab } & \text { labrum } \\ \text { L(numeral) } & \text { numbered legpair } \\ \text { numerals } & \text { ring numbers } \\ \text { pac } & \text { posterior angiocoxite } \\ \text { pb } & \text { posterior branch of angiocoxite } \\ \text { pf2 } & \text { prefemur of legpair } 2 \\ \text { s } & \text { sternum of gonopods } \\ \text { s(numeral) } & \text { sternum of numbered legpair } \\ \text { t9 } & \text { telopodite of legpair 9 } \\ \text { tel } & \text { telson } \\ \text { vd } & \text { openings of } v a s a \text { deferentia } \\ \end{array}$

\section{Taxonomy}

Family Striariidae Bollman, 1893 
The subfamily is defined by the highly complex gonopods, in which a broad, comb-like branch replaces the flagellocoxites seen in Striariinae. The ninth legs are substantially reduced and the sternum, coxae and telopodites are fused. See also the Notes sections below, under the description of the new genus.

\section{Genus Stegostriaria Shear \& Marek, new genus}

Type species: Stegostriaria dulcidormus Shear \& Marek, new species

Etymology: The name of the genus is a feminine Latin neologism based on the name of the dinosaur genus Stegosaurus Marsh, 1877 and the type genus of the Striariidae, Striaria. Species of Stegosaurus are unusual in having a double row of crest-like plates down the back; the enlarged second crests of Stegostriaria $\mathbf{n}$. gen. recall this character.

Diagnosis: A genus of the subfamily Trisariinae, distinct from Trisaria Shear, 2020 in having the second metazonital crests on each side exaggerated and in the presence of intercalary crests between the median sulcus and the first crests (Figs 2-4). The ninth legs of males (Fig. 18) are elaborately modified, unlike those in any other striariids.

Description: See the description of the type and only species, below.

Distribution: Presently known only from Linn and Tillamook Counties, Oregon, USA.

Notes: The discovery of a second genus requires some modifications to the description of the subfamily Trisariinae. The suppression in Trisaria species of the fourth crests is not seen in Stegostriaria, where the third to sixth crests are subequal (Figs 2, 3). Likewise, the gonopod colpocoxite in Stegostriaria $\mathbf{n}$. gen. is not a poorly sclerotized posterior lobe but modified into a long, many-branched structure (cc, Figs 14, 15, 17). While the ninth legs of males show a considerable degree of fusion, both the coxal and telopodite regions show elaborate modifications (Fig. 18)

\section{Stegostriaria dulcidormus Shear \& Marek, new species \\ Figs 1-18}

Types: Male holotype and male paratype from Sweet Home Road, 4 miles WNW of Upper Soda, Linn Co., Oregon, USA, $44.40845^{\circ} \mathrm{N},-122.3843^{\circ} \mathrm{W}, 1680^{\prime}$ asl, collected 2 July 2001 by Jessica Rykken. Parts of the holotype are mounted on SEM stub WS34-2 and parts of the paratype on SEM stub WS10-1. Male and female paratypes from Forest Road 14, 2.2 miles NE of State Route 22, Siuslaw National Forest, Tillamook Co., Oregon, USA, $45.22483^{\circ} \mathrm{N},-123.83867^{\circ} \mathrm{W}, 900^{\prime}$ asl, collected 10 December 2005 by C. Richart and W. Leonard. Parts of the male paratype are mounted on SEM stub WS34-3. Male paratype from Munson Creek Falls State Natural Site, Munson Creek Road, 1.5 miles E of Federal Highway 101, Tillamook Co., Oregon, USA, 45.3650 ${ }^{\circ} \mathrm{N},-123.7790^{\circ} \mathrm{W}, 1710-$ 1750' asl, collected 3 April 2008 by C. Richart and S. Derkarabetian. All types including SEM stubs deposited in the California Academy of Sciences, San Francisco, California, USA.

Etymology: The species name is a Latin neologism, a noun in apposition composed of the words dulcis (sweet) and dormus (home), and refers to the holotype locality.

Diagnosis: See the diagnosis of the genus, above. This is the only known species.

Description: Male paratype from Sweet Home Road. Length $c a$. $8.5-9.0 \mathrm{~mm}$, width $c a .0 .8-1.0 \mathrm{~mm}$. Thirty postcephalic rings including telson.

Head densely setose, with light, pebbled sculpture; labrum (lab) smooth, labral corners rounded, without projecting hook (Fig. 1); 5-7 poorly pigmented ommatidia on each side. Antennae short, robust. Mandibular stipes with finely saw-toothed distal edge and blunt apical lobe (Fig. 1).

Collum broadly expanded, with 10 low crests occupying posterior $5 / 6^{\text {th }}$. Second ring with all crests subequal. Second crests slightly exaggerated on third ring; on subsequent rings second crests 4-5 times higher than others, intercalary crests developing between median sulcus and first pair of crests (Figs 2-4). Limbus of metazonites serrate (Fig. 5). Metazonital setae not observed, possibly absent. 

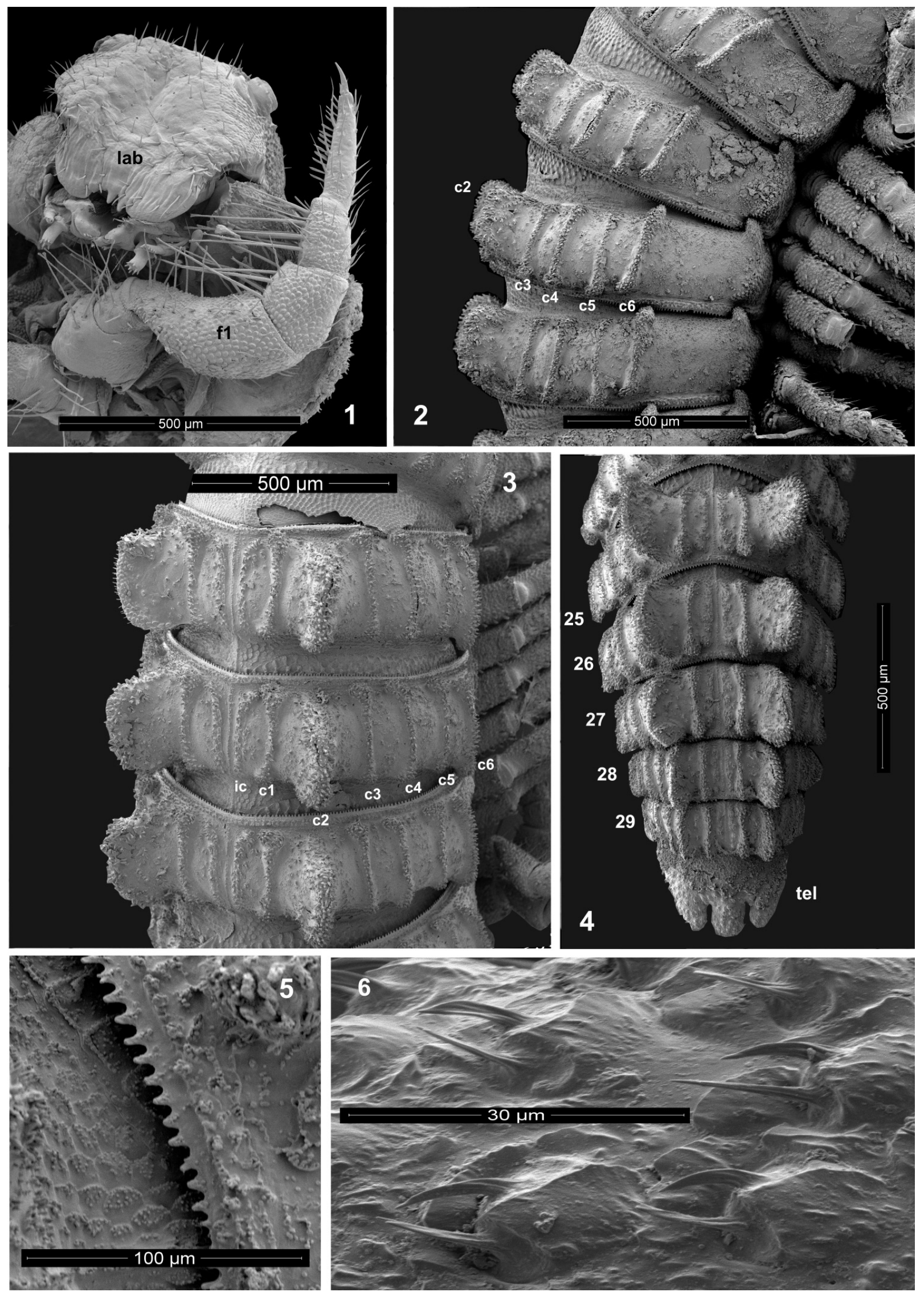

FIGURES 1-6. Stegostriaria dulcidormus n. gen., n. sp., male paratype. 1. Head and leg 1, ventral view. 2. Midbody rings, lateral view. 3. Midbody rings, oblique dorsal view. 4. Rings 25-29 and telson, dorsal view. 5. Limbus, dorsal view. 6. Sculpture of telson, dorsal view. 

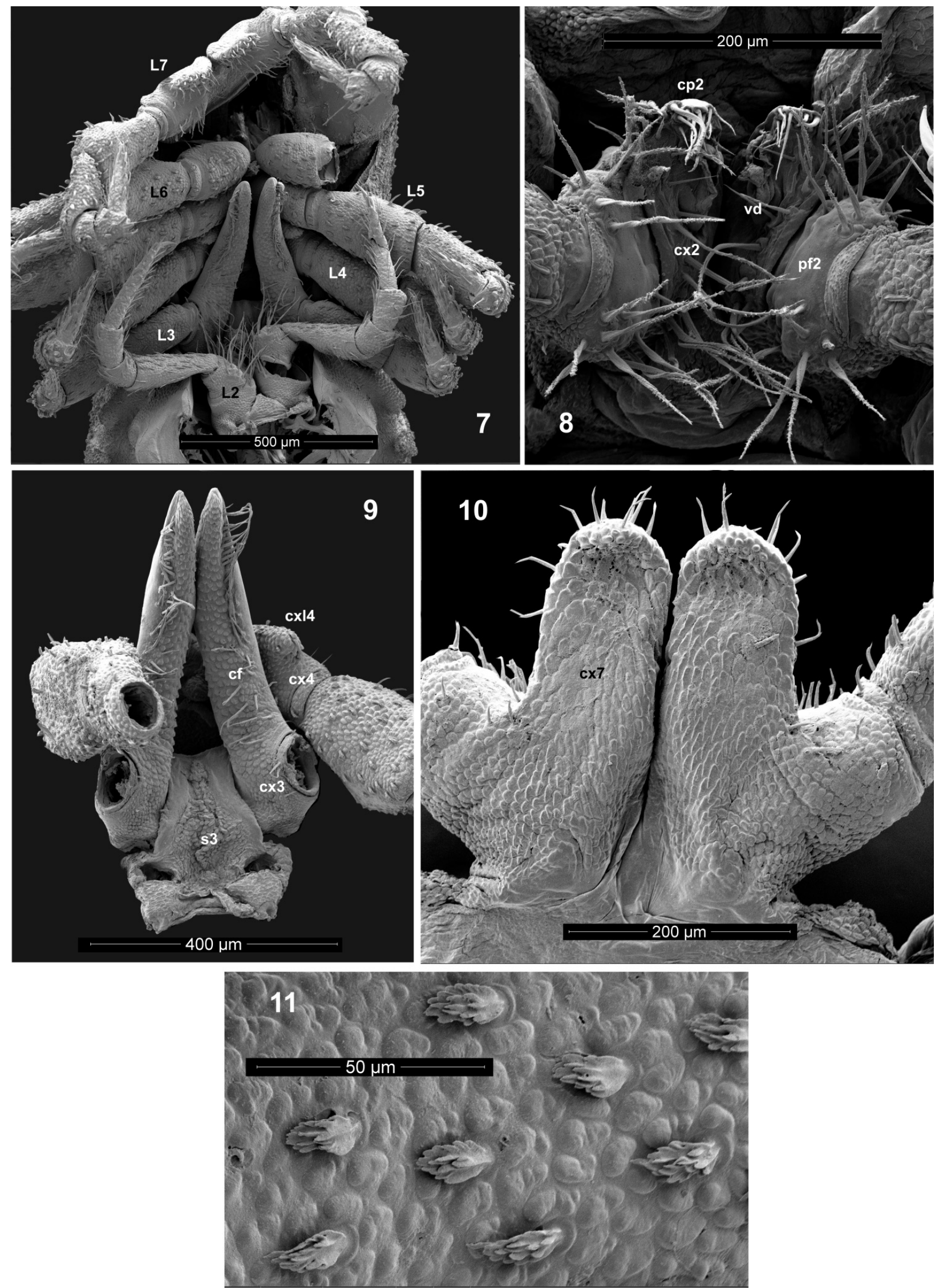

FIGURES 7-11. Stegostriaria dulcidormus n. gen., n. sp., male paratype. 7. Legpairs 2-7, ventral view. 8. Coxae and prefemora of legpair 2, ventral view. 9. Sternum and coxae of legpair 3 and coxae and prefemora of legpair 4, ventral view. 10. Coxae of legpair 7, anterior view. 11. Setae from prefemur of legpair 6, ventral view. 
Telson with deep incisions between lobes (Fig. 4); without crests, sculpture of low tubercles each with two posterior-pointing, acute processes (Fig. 6).

First legpair enlarged, larger than second or third legpair, set with long, needle-like, apically bifurcate setae; tarsi with ventral comb of flattened, twisted setae (Fig. 1). Second leg pair with reduced telopodites (Fig. 7); coxae (cx2) enlarged, bearing opening of vas deferens (vd), with prominent anterior process (cp2) set with long, serrate setae; prefemora (tr2) somewhat enlarged, also with serrate setae (Fig. 8). Third legpair with long, curved coxal flasks (cf) directed posteriorly, anterior row of curled setae, telopodites a little larger than those of second legs (Figs 7, 9). Fourth legpair coxae (cx4) bearing posteriodistal lobe (cxl4), telopodites enlarged (Fig. 7). Fifth and sixth legpairs with enlarged, but not flattened telopodites (Fig. 7). Seventh legpair with enlarged coxae (cx7) bearing strong lobes (Fig. 10), telopodites elongate, prefemur distally swollen (Fig. 7). All legs with scattered, flattened setae with finger-like projections (Fig. 11) becoming longer and more slender on distal podomeres, transitioning on tarsi to flattened, serrate-edged setae with long, filamentous projections (Fig. 12).
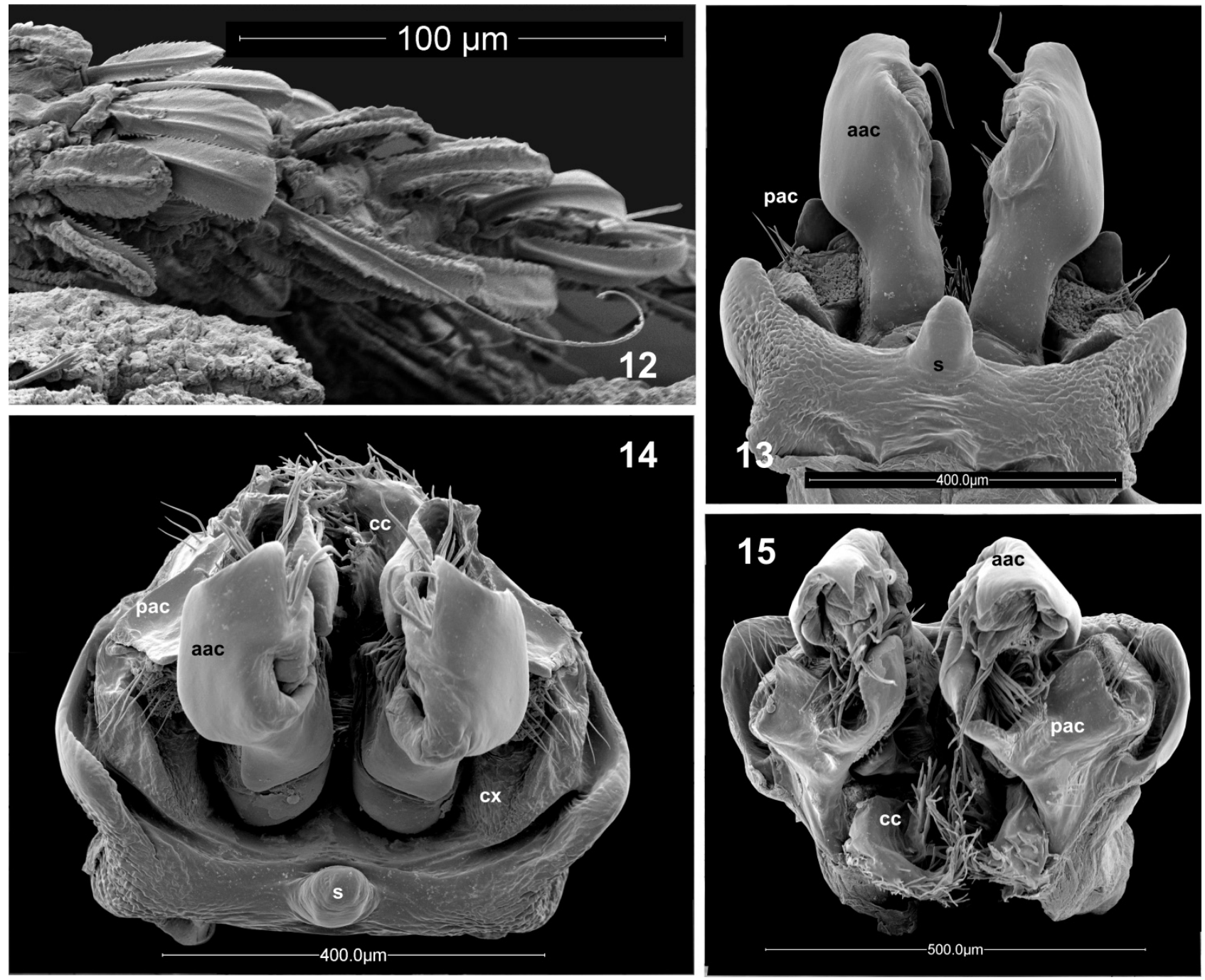

FIGURES 12-15. Stegostriaria dulcidormus n. gen., n. sp., male paratype. 12. Tarsal setae of legpair 34, lateral view. 13. Gonopods, anterior view. 14. Gonopods, ventral view. 15. Gonopods, posterioventral view.

Gonopods (Figs 13-17) small, complex. Gonopod sternum completely encircling gonopods but for small median posterior gap, with central knob and lateral flaring wings (s, Figs 13, 14). Coxae elongate laterally, possibly fused in midline, with two groups of setae (cx, Fig. 14). Anterior angiocoxites (aac, Figs 13-17) divided, anterior branch (ab, Fig. 17) apically blunt, posterior branch (pb, Fig. 17) with 3 or 4 long, acute apical processes; seen basally in anterior view, anterior angiocoxite supports linear array of long, thin, curved processes forming a comb (Fig. 17). Posterior angiocoxites (pac, Figs 13-17) complexly lobed, basally with irregular array of fimbriae (Figs 15, 17). Colpocoxites not divided, present as acuminate lobe divided into many fimbriae (cc, Figs 15, 17). Ninth leg 
pair strongly reduced, sternum (s9), coxae (cx) and telopodites (t9) fused (Fig. 18); coxae with bifurcate distomesal processes (cp, Fig. 18); telopodites largely smooth, lobed, with tuft of stout setae (t9, Fig. 18).

Female paratype closely similar to male in all nonsexual characters.

Distribution: Known only from Linn and Tillamook Counties in Oregon, USA. The Tillamook localities are within 10 miles of each other, but are separated by about 90 miles from the Linn locality; despite this distance, specimens from the two regions are morphologically inseparable. This species should be looked for in the intervening region.

\section{Subfamily Striariinae Bollman, 1893}

The gonopods of this subfamily are simpler than in the Trisariinae, with the angiocoxites usually undivided, and with a prominent set of flagellocoxites ensheathed by the posterior angiocoxites. The sternum, coxae and telopodites of the ninth legs are separated by articulations.

\section{Kentrostriaria Shear \& Marek, new genus}

Type species: Kentrostriaria ohara Shear \& Marek, new species

Etymology: The name of the genus is a feminine Latin neologism based on the name of the dinosaur genus Kentrosaurus Hennig, 1915, of the family Stegosauridae, and Striaria, the name of the type genus of the family. In addition to the double row of crest-like plates down the back, Kentrosaurus species also have at least one lateral crest projecting above the forelimbs, recalling that Kentrostriaria $\mathbf{n}$. gen. has, on the anterior metazonites, enlarged third crests extending somewhat laterally.

Diagnosis: A genus of the subfamily Striariinae, distinct from Amplaria Chamberlin, 1941 and Striaria Bollman, 1888 in having the second metazonital crests on each side exaggerated, as well as the third crests on anterior segments, and in having the gonopod colpocoxites reduced or absent.

Description: See the description of the type and only species, below.

Distribution: Presently known only from Idaho Co., Idaho, USA.

Notes: Unexpectedly, the conformation of the gonopods mandates the placement of this genus in the subfamily Striariinae. Instead of the comb-like structure typical of the gonopods of the trisariines, Kentrostriaria species have at least two gonopod flagellocoxites that are sheathed by the posterior angiocoxites. Unlike trisariines, in which the ninth legs are reduced and fused into a single unit (and in Stegostriaria n. gen. strongly modified), the sternum, coxae and telopodites of Kentrostriaria species are separate and distinct.

\section{Kentrostriaria ohara Shear \& Marek, new species}

Figs 19-26

Types: Male holotype and female paratype from the O'Hara Bar Campground on the Selway River, Nez Percé National Forest, Idaho Co., Idaho, USA, $46.08521^{\circ} \mathrm{N},-115.51761^{\circ} \mathrm{W}, 1600$ ' asl, collected 14 October 2006 by C. Richart, W. Leonard and A. Fusek. The male holotype and female paratype are mounted on SEM stub WS36-18. An additional female paratype is from the same locality, but collected 2 April 2003 by W. Leonard, J. Bough and J. Degenhardt. All types including SEM stubs deposited in the California Academy of Sciences, San Francisco, California, USA.

Etymology: The species epithet is a noun in apposition, after the type locality.

Diagnosis: See the diagnosis of the genus, above. This is the only known species.

Description: Male holotype. Length, ca. 4.5-5.0 mm, width $c a$. 0.4-0.5 mm. Twenty-nine thoracic rings, including telson.

Head densely setose, with minimal pebbled sculpture. Antennae as usual for family. Two black ommatidia on either side of head. Labrum without lateral processes. Mandibular stipes with slight serrate distal edge, lacking acute posteriodistal corner. 

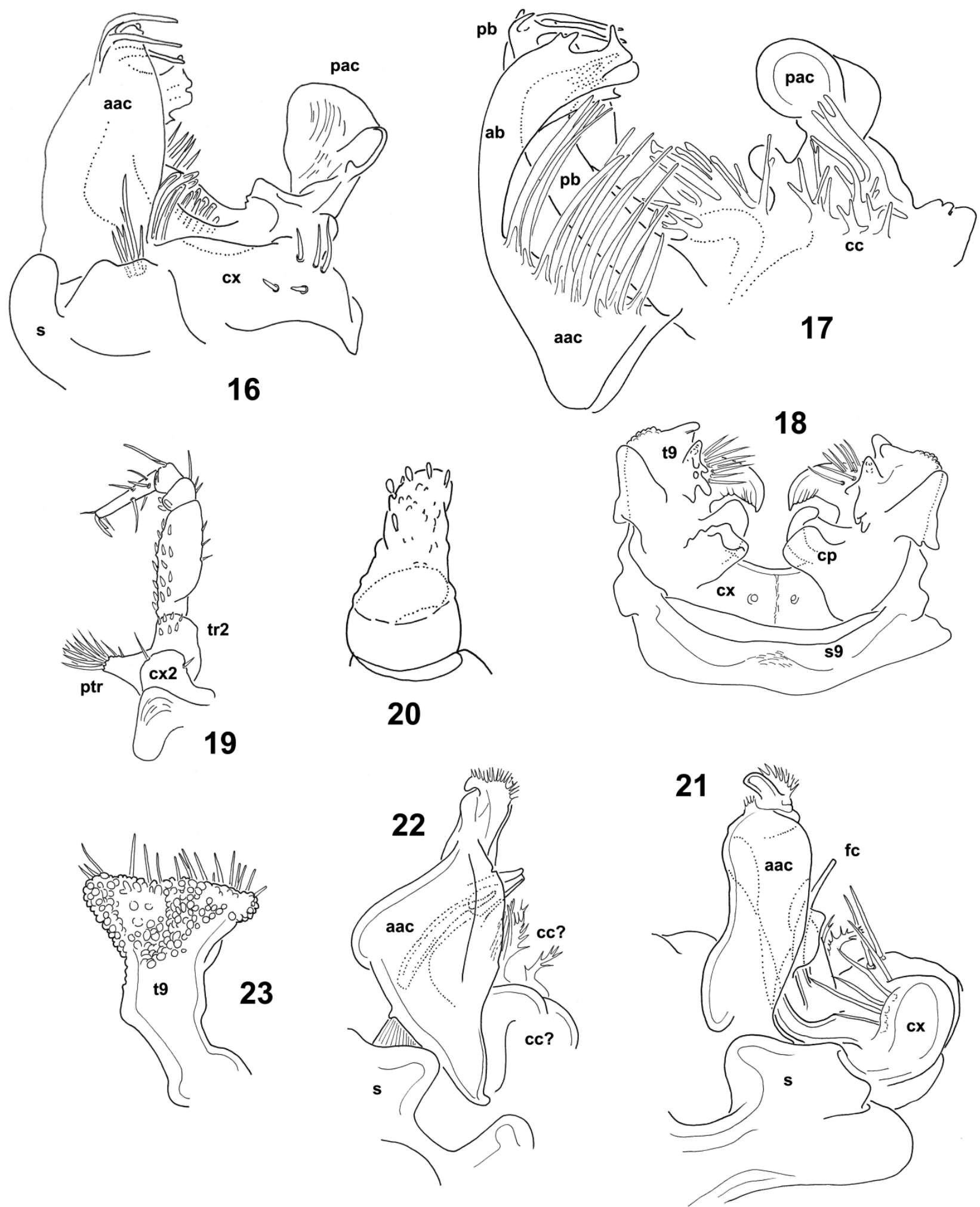

FIGURES 16-23. New species of striariid millipeds. Figs 16-18. Stegostriaria dulcidormus n. gen., n. sp., male paratype. 16. Right gonopod, lateral view, anterior to the left. 17. Left gonopod, mesal view, anterior to the left. 18. Legpair 9, anterior view. Figs 19-23. Kentrostriaria ohara n. gen., n. sp., male holotype. 19. Left leg 2, posterior view. 20. Gonophore, anterior view. 21. Right gonopod, anterior view. 22. Left gonopod, anteriomesal view. 
Collum with distinct pebbled sculpture throughout, crests low, inconspicuous, restricted to posterior half; collum with distinct anteriolateral notches on each side, from which originate lateralmost segmental setae (Fig. 24). Collum with long, acute segmental setae, but such setae not detectable on more posterior trunk rings. Rings 2 and 3 with subequal but prominent crests. Rings 4-6 with both second and third crests exaggerated; second crests the highest, divergent (Fig. 25). From ring 7 posterior, third crest returns to normal size while sixth crest becomes slightly larger (Figs 26, 27).

Telson with lobes not separated by deep incisions, without crests (Figs 25, 26).

First, second and third legpairs subequal in size, first legpair with long setae, third coxae with moderately developed coxal flasks. Second leg prefemor (tr2, Fig. 19) with prominent setose process (ptr, Fig. 19), coxa with vas deferens opening at tip of short process, membranous but with small, scale-like setae (Fig. 20). Fourth to seventh legpairs encrassate. Seventh legpair without coxal lobes.

Gonopods (Figs 21, 22) very small. Sternum (s, Figs 21, 22) prominent, with deep medial embayment. Coxae (cx, Fig. 21) with array of about 6 stout setae. Anterior angiocoxite (aac, Figs 21, 22) not divided, tipped with array of fine cuticular projections. Posterior angiocoxite reduced, sheathing at least two flagellocoxites (fc, Fig. 21). Colpocoxite apparently reduced, posterior part with fimbriate branches (cc?, Fig. 22). Ninth legs with all elements free, telopodite (t9, Fig. 23) flattened, heavily pebbled.

Female paratype. Similar to male, but second crests much lower on posterior segments than in male (Fig. 28).

\section{Key to genera of Striariidae}

1a. Ninth legs of males with telopodites, coxae and sternum fused; gonopod anterior angiocoxites divided into mesal and lateral branches; flagellocoxites absent. . . . . . . . . . . . . . . . . . . .

1b. Ninth legs of males with all elements free; gonopod anterior angiocoxites not divided; flagellocoxites present ...........

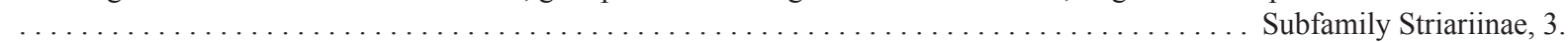
Second crests of metazonites much larger than the others $\ldots \ldots \ldots \ldots \ldots \ldots \ldots \ldots \ldots \ldots \ldots \ldots \ldots \ldots \ldots \ldots \ldots$ Stegostriaria.

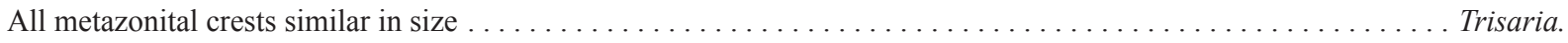
Second, and on some rings, third crests of metazonites larger than others; 29 thoracic rings . . . . . . . . . Kentrostriaria.

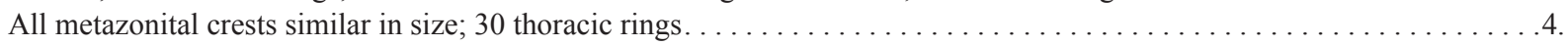

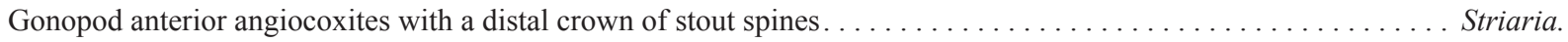
Gonopod anterior angiocoxites without such a crown of spines $\ldots \ldots \ldots \ldots \ldots \ldots \ldots \ldots \ldots \ldots \ldots \ldots \ldots \ldots$ Ampla.

\section{Modified setae}

In addition to the many unique characters that set them apart from other chordeumatidan families, striariids possess a wide array of strikingly modified setae, primarily on the legs. Some of these setae have been described and illustrated previously, as they appear in other genera (For Trisaria, see Shear (2020, figs 25, 45, 46); for Amplaria, see Shear (2021a, figs 16, 17, 23); for Striaria, see Shear (2021b, figs 4, 7, 8). In many striariid species, the femora to tibiae of the first legpair of the males carry long, needle-like, stiff setae with a slight terminal bifurcation (Fig. 1), while the tarsi have a comb of flattened, twisted setae (Fig. 1). The coxae and prefemora of the second legpair of the males bear long, irregularly curved setae that are serrate (Fig. 8). These modified setae are found only in the males. Leg setae of both sexes, particularly on the anterior legs, nearly always show a progressive change from thick, flattened structures with a prominent central ridge or with numerous, blunt, finger-like projections (Fig. 11) to much less modified setae on the more distal podomeres. However, in Stegostriaria dulcidormus n. gen., n. sp., the setae of the proximal podomeres (Fig. 11) transition to flattened, serrate-edged structures with a long filament arising from beneath (Fig. 12). A functional basis for these varied setal modifications is hard to envision.

An important character of the order Chordeumatida is the presence of a series of six prominent setae on the collum and each metazonite. In basal families such as Cleidogonidae, these setae are short and acuminate, while in others, such as Conotylidae and Trichopetalidae, they may be much longer, and by extruding glue from their bases, provide some degree of defense for these millipedes, which lack repugnatorial glands. In the superfamily Striarioidea, there appears to be a tendency for these metazonital setae to be reduced, to take unusual forms, or even to be apparently lost. In the two new species described here, Stegostriaria dulcidormus n. gen., n. sp. appears to lack them entirely; they could not be detected even under the scanning electron microscope, as seems to be the case with at least the Striaria species known from Idaho. In species of Amplaria, the setae vary in length from quite obvious to very short, and with brush-like tips. Kentrostriaria ohara n. gen., n. sp. has long setae on the collum, but none could be detected on the trunk rings (Fig. 22). 

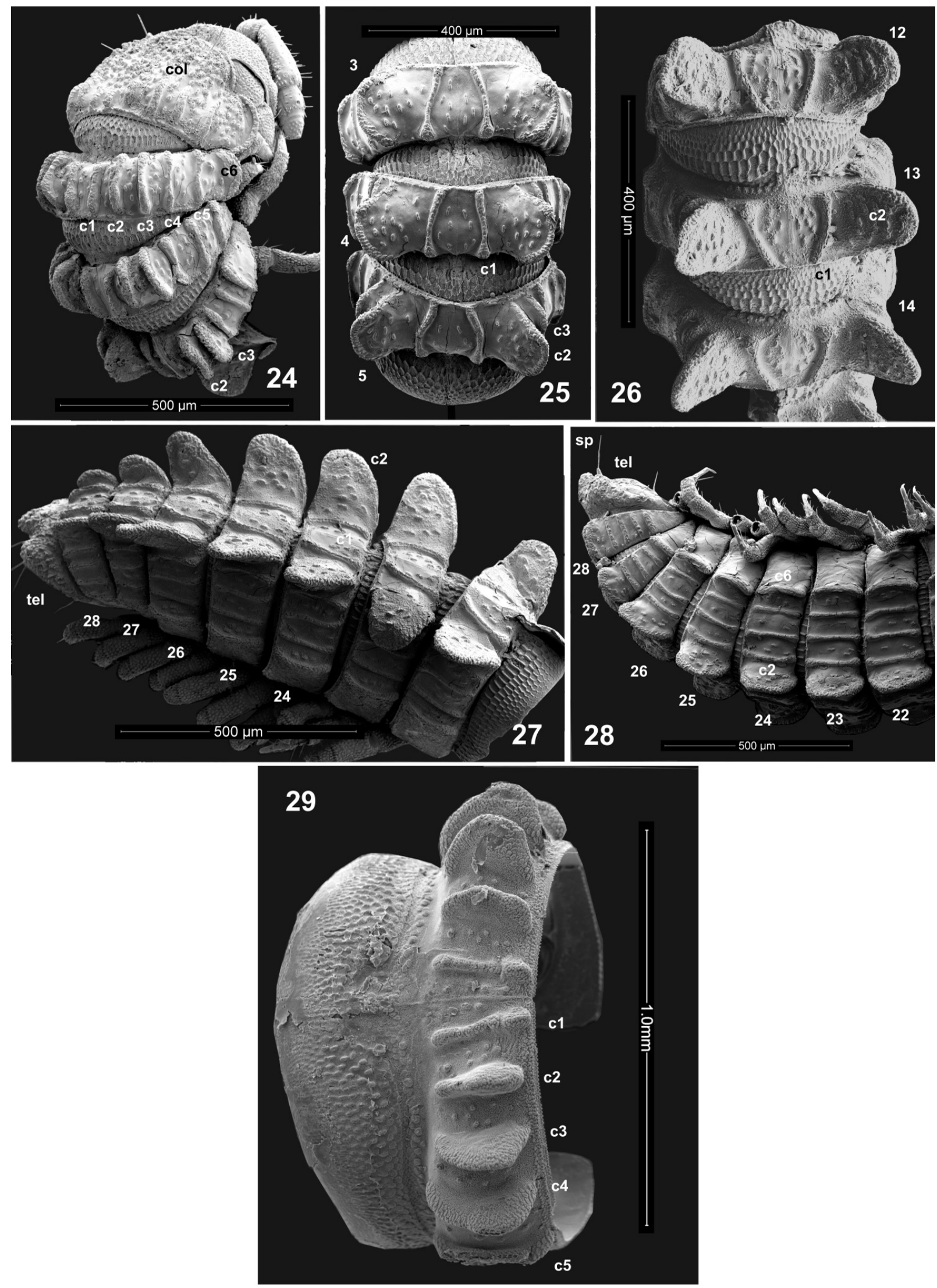

FIGURES 24-29. Striariid millipedes. Figs 24-27. Kentrostriaria ohara n. gen., n. sp. male holotype. 24. Head, collum and rings 2-4, oblique view. 25. Rings 3-5, dorsal view. 26. Rings 12-14, dorsal view. 27. Rings 22-28 and telson, oblique view. 28. Kentrostriaria ohara $\mathbf{n}$. gen., n. sp. female paratype, rings 22-28 and telson, lateral view. 29. Midbody segment of undescribed Striaria species from Waterrock Knob, North Carolina, dorsal view. 


\section{Exaggerated crests and convergent evolution}

The many distinctions between the two genera described above and the significant geographic separation of the two leads to the hypothesis that the "stegosaurid" appearance in species of two distinct subfamilies is due to convergent evolution. The convergence hypothesis is strengthened by the recent discovery of a similarly adapted species of the genus Striaria occurring on the summit of Waterrock Knob, one of the highest peaks along the Blue Ridge Parkway in North Carolina. The undescribed Striaria, however, is still different in that while the second crests are exaggerated, so are the third and fourth (Fig. 29). While crested segments are not known from other chordeumatidans, crested species occur in other millipede orders, such as Glomerida, Spirostreptida, Callipodida and Polydesmida, and a few polydesmidans in the family Pyrgodesmidae even have a "stegosaurid" appearance (i.e., Myrmecodesmus acona (Shear, 1973)). One possible function of crested segments might be to resist crushing forces while limiting the thickness of the exoskeleton. A similar hypothesis has been put forward to explain the heavy crests on shells of many Gastropoda (i.e., Kemperman \& Gittenberger 1988). However, this would not particularly explain why certain crests become so much larger than the others.

But without a strict analysis, an alternative hypothesis of exaggerated crests being the ancestral condition for the family Striariidae cannot be entirely dismissed. Against this hypothesis is the fact that the pattern of enlargement is different in each of the species. In Stegostriaria dulcidormus n. gen., n. sp., only the second crests are affected, while in Kentrostriaria ohara n. gen., n. sp., both the second and third (at least in the anterior part of the trunk) are enlarged and in the undescribed North Carolina Striaria species, the second, third and fourth are all exaggerated. The "stegosaurid" pattern of crest enlargement is not the only one. We have in preparation a study of a number of genera and species of striariids, also from the Pacific Northwest of North America, in which the sixth crest of each side is exaggerated, giving the animals somewhat the appearance of polydesmid millipedes, with their prominent paranota.

\section{Acknowledgements}

We thank Virginia Tech's NFCL (ICTAS) for access to scanning electron microscopy, facilitated by a grant from the National Science Foundation of the United States (\#1916368) to Paul Marek at Virginia Tech and Michael Caterino at Clemson University. We are also grateful to the collectors named in species accounts, above. Their assiduous efforts in obtaining and sending us a steady stream of material from a biologically rich region, the fauna of which is still largely unstudied, is greatly appreciated. We also thank Dragan Antic and Thomas Wesener for detailed reviews which improved the manuscript.

\section{References}

Bollman, C.H. (1888) Notes upon a collection of Myriapoda from East Tennessee, with a description of a new genus and six new species. Annals of the New York Academy of Sciences, 4, 106-112. https://doi.org/10.1111/j.1749-6632.1889.tb57035.x

Bollman, C.H. (1893) The Myriapoda of the United States. United States National Museum Bulletin, 43, 1-210.

Bond, J.E., Godwin, R.L., Colby, J.D., Newton, L.G., Zahnle, X.J., Agnarsson, I., Hamilton, C.A. \& Kuntner, M. (2021) Improving taxonomic practices and enhancing its extensibility-an example from Araneology. Diversity, 14, 1-15. https://doi.org/10.3390/d14010005

Chamberlin, R.V. (1941) New Western millipeds. Bulletin of the University of Utah, 31 (2), Biological Series, 6, 3-23.

Hennig, E. (1915) Kentrosaurus aethiopicus, der Stegosauridae das Tendaguru. Sitzungberichte der Gesellschaft Naturforschender Freunde zu Berlin, 1915, 219-247.

Kemperman, T. \& Gittenberger, E. (1988) On morphology, function and taxonomic importance of the shell ribs in Clausiliidae (Mollusca: Gastropoda: Pulmonata) with special reference to those in Albinaria. Basteria, 52, 77-100. [https://natuurtijdschriften.nl/pub/596881]

Marsh, O.C. (1877) A new order of extinct Reptilia (Stegosauria) from the Jurassic of the Rocky Mountains. American Journal of Science, 3, 513-514. https://doi.org/10.2475/ajs.s3-14.84.513

Shear, W.A. (1973) Millipeds from Mexican and Guatamalan caves. Accademia Nazionale dei Lincei, Problemi attuali di scienza e di cultura, 171, 239-305.

Shear, W.A. (2020) The millipede family Striariidae Bollman, 1893. I. Introduction to the family, synonymy of Vaferaria Cau- 
sey with Amplaria Chamberlin, the new subfamily Trisariinae, the new genus Trisaria, and three new species (Diplopoda, Chordeumatida, Striarioidea). Zootaxa, 4758 (2), 275-295.

https://doi.org/10.11646/zootaxa.3109.1.1

Shear, W.A. (2021a) The millipede family Striariidae Bollman, 1893. II. New records and species of the genus Amplaria Chamberlin, 1941 (Diplopoda, Chordeumatida, Striarioidea). Zootaxa, 4908 (2), 205-224.

https://doi.org/10.11646/zootaxa.4908.2.3

Shear, W.A. (2021b) The millipede family Striariidae Bollman, 1893. III. Four new species of Striaria Bollman, 1888 (Diplopoda, Chordeumatida, Striarioidea). Zootaxa, 4920 (3), 395-406.

https://doi.org/10.11646/zootaxa.4920.3.5 